\title{
Physicochemical, microbiological, and sensory characterization of fermented coffee pulp beverages
}

\author{
Claudia Milena Amorocho Cruz $^{1}$ (D), Yenifer Muñoz Cortés ${ }^{1}$ (iD
}

${ }^{1}$ Universidad Surcolombiana/USCO, Facultad de Ingeniería, Programa Ingeniería Agrícola, Neiva, Huila, Colombia

Contact authors: claudiamilena.amorocho@usco.edu.co, yennifer1393@hotmail.com

Received in January 20, 2021 and approved in June 16, 2021

\begin{abstract}
Coffee pulp is the first by-product generated from coffee processing, a contaminating residue due to its composition and production volume. So, this research presents the use of coffee pulp with honey and sugar cane juice to elaborate alcoholic beverage and infusion. The harvested coffee was washed, pulped; the pulp was distributed in 3 treatments, by duplicates, $(T)$ coffee pulp and water, (M) coffee pulp, water and honey, (G) coffee pulp and sugar cane juice. Then, each treatment was brought to $85^{\circ} \mathrm{C}$ for 15 minutes, warmed up and yeast was added to each container. Fermentation was carried out for 14 days at $15^{\circ} \mathrm{C}$. After the liquid was separated from the pulp, the liquid fraction was left to ferment another 14 days, it was clarified with bentonite, it was bottled and for 102 days mature, the degrees of alcohol was measured by simple distillation. The pulp was placed in an oven at $75^{\circ} \mathrm{C}$ for 3 days, the chemical composition was analyzed by FTIR, it was packed in hermetic bags, the dry coffee pulp was used to prepare an infusion. For its use, a fermented drink and an infusion were elaborated, evaluating physicochemical, microbiological, and sensorial characteristics through three treatments. The fermented drinks presented values of alcohol degrees $7^{\circ}-6^{\circ}$. The treatment with honey obtained a greater acceptance followed by the treatment with sugar cane juice. The infusions were acceptable, differentiated by herbal notes, pleasant aromas, and sweet flavors. In the pulp, the following were characterized by FTIR chemical compounds and wavelengths that show their absorbencies; caffeine with ranges of $2920-2850$ and $1620 \mathrm{~cm}^{-1}, 3280 \mathrm{~cm}^{-1} \mathrm{H}_{2} \mathrm{O}, 1740 \mathrm{~cm}^{-1}$ lipids, $1240 \mathrm{~cm}^{-1}$ chlorogenic acid, and $1015 \mathrm{~cm}^{-1}$ carbohydrates. Finally, the infusions with coffee pulp were accepted by the evaluators, especially those that went through the fermentation process with honey and sugar cane.
\end{abstract}

Keywords: Caffeine; Coffee; Chemical compounds; Fermentation; Sensory analysis.

\section{INTRODUCTION}

The main coffee producers in the world are Brazil, Vietnam, Colombia (García-Freitas; Röder; Thornley, 2020), Indonesia, and Etiopía (Duarte et al., 2021). In the coffee production chain, only $5 \%$ of the total weight of the coffee fruit is used for the preparation of beverages and the remaining $95 \%$, by-products (Rodríguez, 2011) as pulp, mucilage, parchment (cisco), pasilla (the moldy, overcooked, or shriveled leftovers from commercial coffee production) and honey water are generated, which in most cases are difficult to handle and have high perishability. The average production of pulp is 2.25 tons.ha ${ }^{-1}$.year ${ }^{-1}$ (Rodriguez, 2013). 1670 tons of cellulose, 593 thousand tons of mucilage; despite their high lignocellulosic value, these agricultural residues are not properly exploited (Duarte et al., 2021). The use of agroindustrial residues in bioprocesses helps to reduce environmental pollution (Corro et al., 2013); about coffee Pulp, there is a problem with these by-products because are discarded in rivers and soils, contaminating the ecosystem and implying economic losses for producers (Rodríguez, 2011). Then, Colombia with developed economies should implement the complementary application of your main export product (Duarte et al., 2021).

Throughout time, research has been carried out on the chemical and microbiological composition of the coffee pulp, to obtain value-added products, such as compost production (Pushpa; Madhava, 2012). Direct use for animal feed is limited due to the presence of anti-nutritional factors such as caffeine and tannins (Esquivel, 2012). The addition of pulp to feed ruminants, pigs, chickens, and rabbits has been reported (Pushpa; Madhava, 2012). Coffee husks can also be used for mushroom cultivation. By fermentation with Aspergillus, citric acid, gibberellic acid, and enzymes have been produced (Pandey et al., 2000). Yeasts, fungi, and Zymomonas Mobilis produce bioethanol (Duarte et al, 2021) and promising aromatic compounds in the shell or pulp of coffee (Bonilla; Duarte; Schwan, 2014). Attempts have also been made to use the coffee pulp for biogas production (Pandey et al., 2000).

Coffee cherry pulp was shown to be a potential source of antioxidants and phenolic compounds that should not be wasted. Since coffee cherry pulp and coffee beans contain similar components, the dried coffee cherry pulp can be used to produce a refreshing and stimulating beverage called cáscara (the Spanish word for hulk or chaff). Cascara, also known as coffee cherry tea, is an infusion of dried coffee cherry pulp. The approach to valorizing food by-products by preparing an infusion from it has already been described for other agricultural by-products, such as plasticine coffee (Martinez et al., 2014) or buckwheat hooves (Zielinska; Szawara-Nowak; Zielinski, 2013).

It should be noted that the coffee fruit is rich in easily fermentable sugars with values between $10-12^{\circ}$ Brix. However, the fermentation process is optimized by guaranteeing values greater than $20^{\circ}$ Brix. For this reason, an alternative is a chaptalization with honey and sugar cane juice, products that 
are produced in Colombia, where sugar cane juice is a raw material to produce bioethanol (Duarte et al., 2021), and in Europe, honey is used in the production of traditional alcoholic beverage as whiskeys, beer, brandies, and cider because the alcohol content increases due to the greater amounts of sugars available for fermentation. Mead is different depending on the origin of honey, water proportion, add spices, fruit, preparation method (Starowicz; Granvogl, 2020).

In this way, it is proposed to elaborate alternative products derived from the by-products of coffee, an alcoholic beverage with its sensorial profile, and an herbal infusion with the notorious characteristics of a tea. So, we evaluate the process of alcoholic fermentation in coffee pulp using the yeast Saccharomyces cerevisiae (Freddo). Through different fermentation times, physical, chemical, and microbiological parameters will be monitored. After a short maturation process, sensory analysis is performed on the final products.

\section{MATERIALS AND METHODS}

\subsection{Raw material collection}

$30 \mathrm{~kg}$ of cherry (Arabica) coffee variety Caturra was collected from the municipality of San Agustin-Huila, El Porvenir farm. The raw material was processed in the pilot coffee processing plant of the South Colombian Coffee Research Center (CESURCAFÉ) of the Surcolombiana University - Neiva, with a GAVIOTA 300 pulper (300 kg.h $\left.{ }^{-1}\right)$.

\subsection{Treatments}

3 treatments with their respective duplicates were made: firstly, unchaptalized coffee pulp (T) with $2.1 \mathrm{~kg}$ of pulp diluted in 4.9 liters of drinking water; secondly, chaptalized pulp with honey (M) with $2.1 \mathrm{~kg}$ of coffee pulp in 4.9 liters of drinking water chaptalized with bee honey at $16^{\circ} \mathrm{Brix}$; and thirdly, chaptalized pulp with sugar cane set $(G)$ with $2.1 \mathrm{~kg}$ of coffee pulp in 4.9 liters of sugar cane juice (Guarapo) reaching the soluble solids of the same.

\subsection{Pasteurization}

Once the treatments with their respective duplicates were ready, they were taken to $85^{\circ} \mathrm{C}$ for 15 minutes, in order to eliminate microorganisms present in the samples.

\subsection{Fermentation}

$1.5 \mathrm{~g}$ of Saccharomyces cerevisiae var. Bayanus yeast (Freddo, Oenoferm, Germany) was added to each container, in addition to this Vita Drive (F3, Erbslöh, Germany) was added to complete the task of nourishing the yeast during the fermentation process. The containers (Persal, Colombia) containing the inoculated must were sealed. Fermentation was carried out during 14 days $\left(336 \mathrm{~h}\right.$ ), in refrigeration at 15 to $20^{\circ} \mathrm{C}$, optimum temperature for the development of the Freddo yeast. During this time, the growth of the yeast, soluble solids, $\mathrm{pH}$, acidity, color and viscosity were monitored.

\subsection{Clarification}

The method used to achieve the decantation of solids in suspension of the respective musts or fermented drink was the addition of Bentonite Food-Grade (Fossil Lower, USA), in an amount of $0.0005 \mathrm{~kg}$ per liter of must. Once the adequate amount was added and after the activation time of bentonite $(24 \mathrm{~h})$, it was homogenized for 10 minutes and left to act for 12 days.

\subsection{Bottling}

After 12 days of the clarification process, the respective treatments were filtered and the clarified drinks were poured into dark bottles, which were previously washed and disinfected. The pouring into the bottles was carried out by difference in height. Finally, the bottles were corked.

\subsection{Maturation}

It was carried out in the food laboratory of the College of Engineering in a period of time of 102 days $30^{\circ} \mathrm{C}$, taking the precaution of storing them in a horizontal position to guarantee that the drink covers the cork inside and thus the entrance of oxygen to the interior of the bottle is prevented.

\subsection{Distillation}

A simple distillation assembly was implemented. $0.25 \mathrm{~L}$ of the fermented drink already matured were taken, maintaining a temperature of $70-80{ }^{\circ} \mathrm{C}$ during an approximate time of 4 hours, two bottles of each treatment were distilled. Using the Gay Lussac equation, the average degrees of alcohol of the fermented coffee pulp drinks were obtained.

${ }^{\circ} \mathrm{GL}=\frac{\text { distilled volumen } \times 100}{\text { drink volume }}$

\subsection{Elaboration of coffee pulp infusion}

The coffee pulp from the different treatments was dried. A ratio of $7 \mathrm{~g}$ of dried coffee pulp per $100 \mathrm{ml}$ of boiled potable water was taken and an infusion time (Resting) of 4 minutes, a filtration was done to remove the solid particles and the beverages were served to be consumed and evaluated.

\subsection{Determination of Physicochemical \\ Parameters}

\section{Soluble Solids ( $\left({ }^{\circ} \mathrm{Brix}\right)$}

It was determined by direct measurement with the digital refractometer PR-201 $\alpha$ brand ATAGO.USA, by the refractometer method (AOAC-932.12). 
pH

For the measurement of this parameter, a digital Starter 5000 potentiometer, brand OHAUS, USA was previously calibrated according to the protocol and analysis described by the AOAC and Standard Methods, potentiometer method (AOAC-981.12).

\section{Titratable Acidity}

Titratable acidity was determined in function of the equivalent to the chlorogenic acid, which is the predominant acid in coffee pulp, according to standard (AOAC-942.15).

\section{Color}

A mobile colorimeter CR-410 HEAD from KONICA MINOLTA, USA was used to measure the parameters of the CIE (International Eclairage Commission) method. The measurement was made with $0.020 \mathrm{~L}$ of sample of the different treatments and CIE coordinates $\mathrm{L}^{*}$, $\mathrm{a}^{*}$ and $\mathrm{b}^{*}$ were obtained (Chiralt et al., 2012), using the D65 illuminant and an observation angle of $10^{\circ}$.

\subsection{Sensory evaluation}

The sensory analysis was conducted at the South Colombian Coffee Research Center (CESURCAFE), by a panel of 30 non-expert judges (Consumers). The acceptance of the following attributes were evaluated: color, limpidity, aroma, flavor, acidity, alcohol, body, aftertaste, and general impression.

\subsection{FTIR Analysis}

Infrared measurements were made with the AGILENT TECHNOLOGIES spectrometer (Cary 630 FTIR, USA), between wavelengths $4000-400\left(\mathrm{~cm}^{-1}\right)$, with a resolution of $4 \mathrm{~cm}^{-1}$ and 20 scanners. The coffee pulp samples from the different treatments were crushed; 1 gram was taken from each one and placed on the lens of the equipment to make the respective measurements. The areas of the reported peaks of interest for caffeine, lipids, chlorogenic acids, carbohydrates, and water were integrated to the obtained spectra.

\subsection{Statistical analysis}

The results obtained were analyzed by means of an analysis of variance (simple and multifactorial ANOVA), with a $95 \%$ confidence level; establishing if there are statistically significant differences in the evaluated variables depending on the evaluated treatments. Tukey HSD difference procedure was used to discriminate among the means. The computer program Statgraphics Centurion XVI Version 16.1.03 was used.

\section{RESULTS}

\subsection{Physicochemical characterization of the \\ fermentation processes between treatments}

The effect of soluble solids was greater in the treatment factor (A) compared to the fermentation time factor (B), as confirmed by the F-ratio results obtained in the statistical analysis (Table 1). In addition, the interaction between the factors (A and B) was determined, in general the parameters present statistically significant differences $(p<0.05)$ with the exception of acidity; showing that soluble solid content determines the fermentation process and therefore ethanol production, which is carried out in the first three days as observed in Figure 1A and stabilizes later. The same trend is present in the other physicochemical parameters.

The behavior of the $\mathrm{pH}$ of the treatments with respect to time, where $\mathrm{T}$ treatment differs significantly in relation to $\mathrm{M}$ and $\mathrm{G}$. In all three treatments, the trend of this parameter is constant and it decreases with the passing of the fermentation time (Figure 1B). It is related to the transformation of the sugars present in alcohol and the desorption of the $\mathrm{CO}_{2}$ generated. The $\mathrm{pH}$ ranges of the treatments are between 4-4.5, being considered slightly acidic. The tendency of acidity in the treatments is to increase with respect to the time of fermentation as it is visualized in Figure 1C. About the behavior of the viscosity of each treatment is shown in Figure 1D where it can be seen that $\mathrm{M}$ and $\mathrm{G}$ treatments present significant differences with respect to $\mathrm{T}$.

Table 1: Behavior of the F-ratio and P-value of the parameters evaluated with respect to treatments and time (d).

\begin{tabular}{|c|c|c|c|c|}
\hline & Parameter & Treatment (A) & Time (days) B & A*B \\
\hline & $\mathrm{L}^{*}$ & $109.28 * * *$ & $141.04 * * *$ & $24.96 * * *$ \\
\hline & $a^{*}$ & $284.77 * * *$ & $45.49 * * *$ & $11.99 * * *$ \\
\hline \multirow[t]{7}{*}{ Color } & $\mathrm{b}^{*}$ & $38.41 * * *$ & $100.83 * * *$ & $21.45^{* * *}$ \\
\hline & $\mathrm{C}$ (chroma) & $197.21 * * *$ & $59.85 * * *$ & $12.93 * * *$ \\
\hline & H (tone) & $646.81 * * *$ & $33.85 * * *$ & $36.99 * * *$ \\
\hline & $\mathrm{pH}$ & $2993.63 * * *$ & $581.75 * * *$ & $9.54 * * *$ \\
\hline & Soluble solids & $26482.31 * * *$ & $3381.51 * * *$ & $593.71 * * *$ \\
\hline & Acidity kg. $\mathrm{L}^{-1}$ & $49.14 * * *$ & $13.39 * * *$ & $1.25^{\mathrm{ns}}$ \\
\hline & Viscosity & $1439.9^{* * *}$ & $252.33 * * *$ & $15.99 * * *$ \\
\hline
\end{tabular}

A: Treatment. B: Time. $A^{*} B$ : Interaction between factors. ns: not significant $p>0.05 .{ }^{*}: p<0.05 .{ }^{* *}: p<0.01 .{ }^{* *}: p<0.001$. 
A) SOLUBLE SOLIDS ( ${ }^{\circ}$ Brix) PER TREATMENT

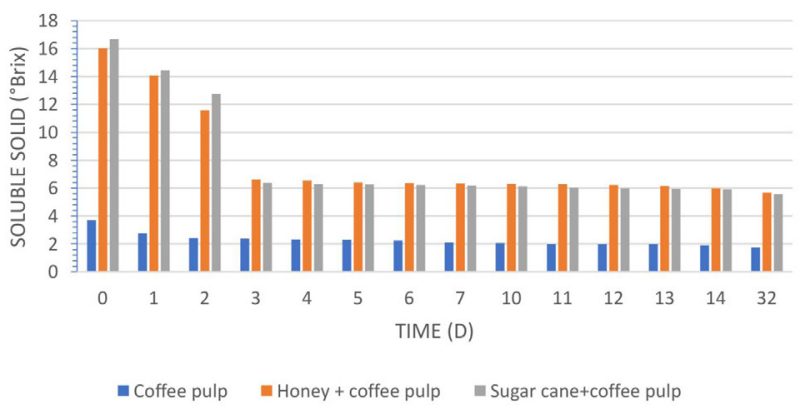

C) ACIDITY PER TREATMENT

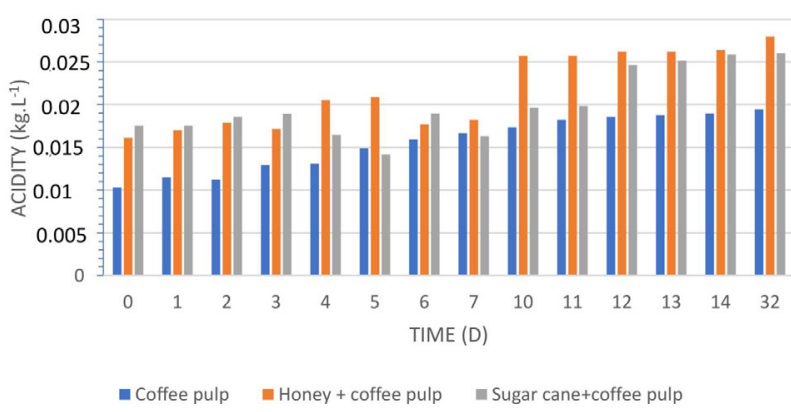

B) $\mathrm{pH}$ PER TREATMENT

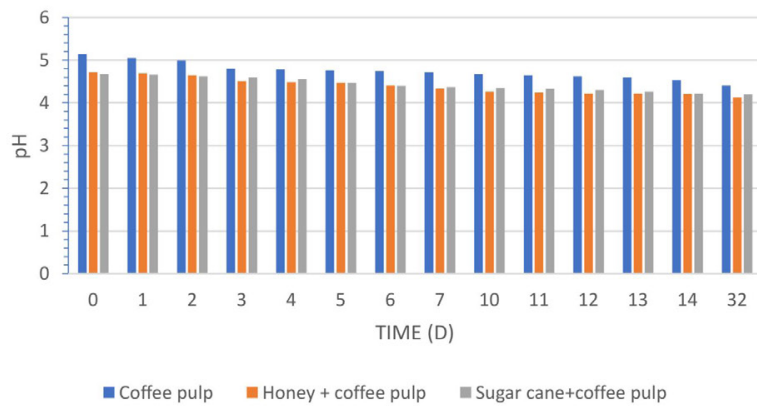

D) VISCOSITY PER TREATMENT

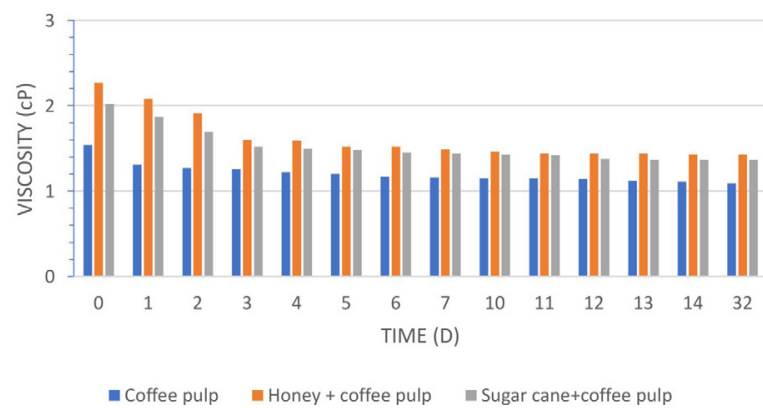

Figure 1: Physicochemical parameters with respect to time (days) of treatments. A: Behavior soluble solid ( ${ }^{\circ}$ Brix). B: Behavior of the $\mathrm{pH}$. C: Behavior of acidity kg.L-1 (chlorogenic acid). D: Behavior of viscosity (cP).

\subsection{Microbiological Analysis}

In the three treatments, the phases of exponential growth are observed, $\mathrm{M}$ and $\mathrm{G}$ treatments reaching it on day 1 and $\mathrm{T}$ treatment reaching its maximum on day 2 (Figure 2). This shows that the greater availability of soluble solids in the $\mathrm{M}$ and $\mathrm{G}$ treatments favors the metabolism of the inoculated yeast, which reaches values of 8.61 and $8.67 \log _{10}$ CFU.mL $\mathrm{mL}^{-1}$ in one day respectively. In the case of developing the yeast in a medium with lower soluble solids content, as it is the case of the $\mathrm{T}$ treatment, one more day was required to reach the maximum microbial growth $8.3 \log _{10}$ UFC.mL ${ }^{-1}$ and with a lower value of viable ones with respect to $\mathrm{M}$ and $\mathrm{G}$ treatments.

The volumes obtained after distillation, when comparing the treatments in relation to the degree of alcohol, it is found that there are statistically significant differences $(\mathrm{p}<0.05)$ (Table 2).

The difference in color $\left(\Delta \mathrm{E}^{*}\right)$ between the treatments. The values obtained indicate that the beverages produced are visually different with respect to the time intervals (Figure 3). $\mathrm{T}$ and $\mathrm{M}$ are visually different since high values are presented with respect to those of G. The phases of initiation, bottling, and maturation (0-32 and 133) of the beverage have a significant impact on $\Delta \mathrm{E}^{*}$ presenting an increase in the color change of the beverage. $T$ and $M$ present statistically significant differences $(\mathrm{P}<0.05)$ with respect to $\mathrm{G}$.

The color parameter was determined by means of the CIELab spacing. Table 3 shows that T, M and G present statistically significant differences ( $>0.005$ ) with respect to the chroma and tone coordinates. The values for $\mathrm{C}^{*}$ obtained are low achromatic, i.e. without any orientation to red, green, blue or yellow, and no highly saturated colors are presented. The results obtained for $\mathrm{H}^{*}$ are between $0^{\circ}$ and $90^{\circ}$, indicating a color with strictly red content.

\subsection{Sensory analysis}

In the time of maturation, special aromas and flavors are developed when tasting the coffee pulp wine. The attributes color, aroma, flavor, aftertaste, and overall impression attributes for the $\mathrm{T}$ and $\mathrm{G}$ treatments do not differ significantly compared to $\mathrm{M}$ which was more widely accepted by judges (Figure 4A). For the limpidity attribute, it is shown that $\mathrm{T}$ presents similarities with $\mathrm{M}$ and $\mathrm{G}$, but these differ between them. In addition, $\mathrm{M}$ stood out more for the judges, indicating that it is a drink without the presence of impurities. In the drink obtained from the different treatments, the body attribute was not highlighted, indicating that the judges neither liked nor disliked this property. In general, the treatment with the greatest acceptance was $\mathrm{M}$, followed by $\mathrm{G}$, and finally $\mathrm{T}$ was the least accepted.

The final behavior of the physicochemical parameters evaluated for the different beverages obtained (Figure 4B, 4D). It is evidenced in T, M and $\mathrm{G}$ decrease in soluble solids and viscosity, these parameters are directly related since high values in soluble solids generate high viscosity (Figure 4B). 


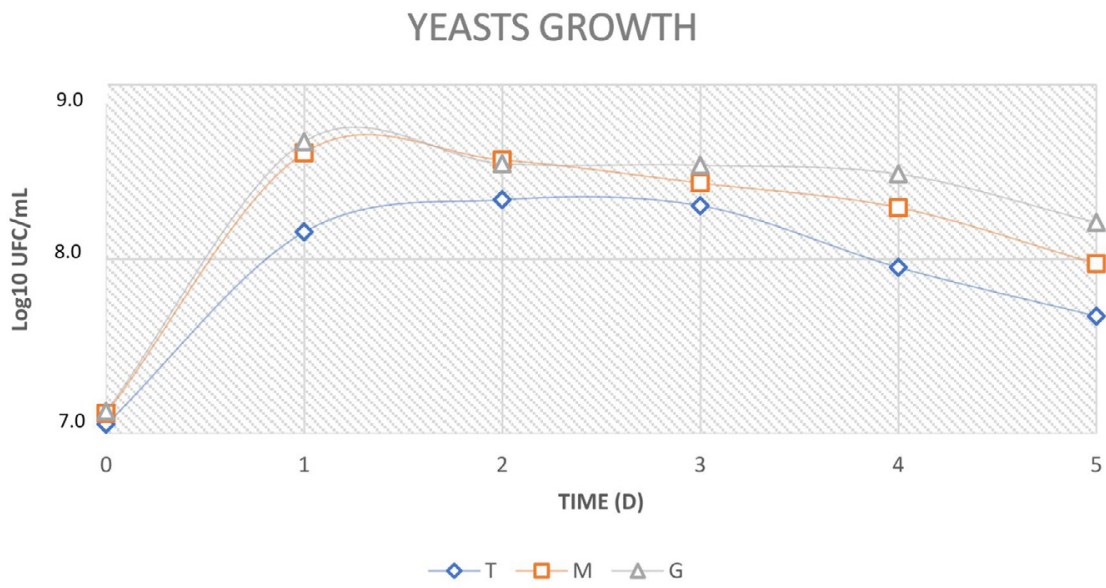

Figure 2: Yeast growth curve of treatments over time. T: coffee pulp. M: Honey + coffee pulp. G: Sugar cane+coffee pulp.

Table 2: Volume obtained in the distillation and alcohol grades of the treatments.

\begin{tabular}{cccc}
\hline Treatment & Sample volume (L) & Volume of distilled alcohol (L) Medium+DS & Grades of alcohol \\
\hline T - Control & 0.250 & $0.0010 \pm 0.06^{\mathrm{a}}$ & 0.41 \\
M- Honey - Pulp & 0.250 & $0.0175 \pm 0.50^{\mathrm{b}}$ & 7.00 \\
G-Sugar cane-Pulp & 250 & $16.00 \pm 0.50^{\mathrm{c}}$ & 6.40 \\
\hline
\end{tabular}

Interacciones y $95,0 \%$ de Fisher LSD

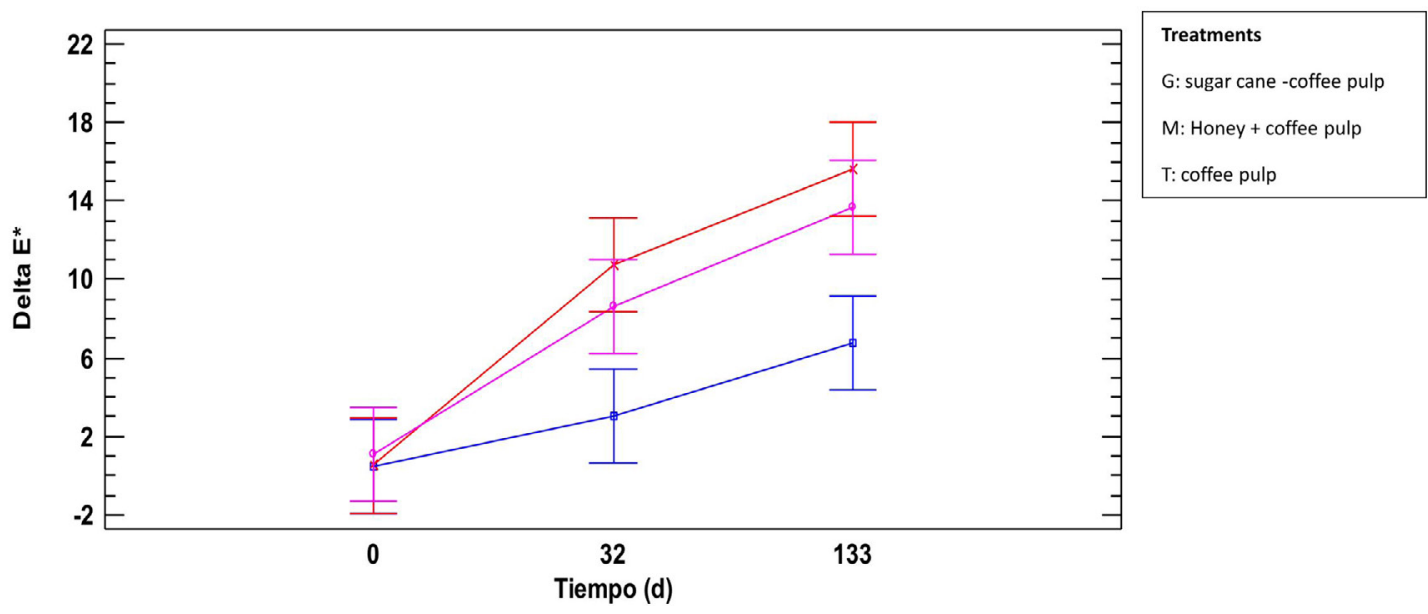

Figure 3: Behavior of $\Delta \mathrm{E}^{*}$ between treatments.

G: sugar cane + coffee pulp. M: honey+coffee pulp. T: coffee pulp.

\subsection{Physicochemical Characterization of Coffee Pulp infusion}

In relation to coffee pulp infusion shows that $M$ and $G$ present similarities in some attributes for the judges, and these treatments are the most widely accepted. The T treatment infusion presented low scores (Table 3) and variations; this is related to the fact that it does not have any type of sweetener attached that modifies certain organoleptic characteristics. The scores obtained did not present high values, which is related to the fact that the evaluators are not habitual tea consumers (Figure 4C).

\subsection{FTIR applied to the coffee pulp of the treatments}

The average spectra obtained for the coffee pulp for each treatment carried out are shown in Figure 5. All the spectra were recorded within a wavelength of $4000-650 \mathrm{~cm}^{-1}$. The absorbency behavior of the treatments $\mathrm{M}$ and $\mathrm{G}$ presents similarity in such characteristic in comparison with $\mathrm{T}$. This is related to the content of humidity present in the coffee pulp of the treatments and the presence of a sweetener in each treatment. 
Table 3: Consolidated mean values and standard deviation of the evaluated parameters of the coffee pulp infusion.

\begin{tabular}{ccccc}
\hline Treatment & Soluble solid ${ }^{\circ}$ Brix & $\mathrm{pH}$ & C (chroma) & H (tone) \\
\hline $\mathrm{T}$ & $0.43 \pm 0.06^{\mathrm{a}}$ & $4.94 \pm 0.01^{\mathrm{a}}$ & $33.95 \pm 0.04^{\mathrm{a}}$ & $67.72 \pm 0.05^{\mathrm{a}}$ \\
$\mathrm{M}$ & $1.57 \pm 0.06^{\mathrm{b}}$ & $4.42 \pm 0.01^{\mathrm{b}}$ & $31.24 \pm 0.05^{\mathrm{b}}$ & $33.57 \pm 0.05^{\mathrm{b}}$ \\
$\mathrm{G}$ & $1.57 \pm 0.06^{\mathrm{b}}$ & $4.66 \pm 0.01^{\mathrm{c}}$ & $28.26 \pm 0.02^{\mathrm{c}}$ & $37.71 \pm 0.03^{\mathrm{c}}$ \\
\hline
\end{tabular}

D.E.: Standard Deviation; a, b, c. Different letters in the same column indicate statistically significant changes from one another $(P<0.05) ; \tilde{x} \pm S D . T$ : coffee pulp. G: sugar cane + coffee pulp. M: honey+coffee pulp.

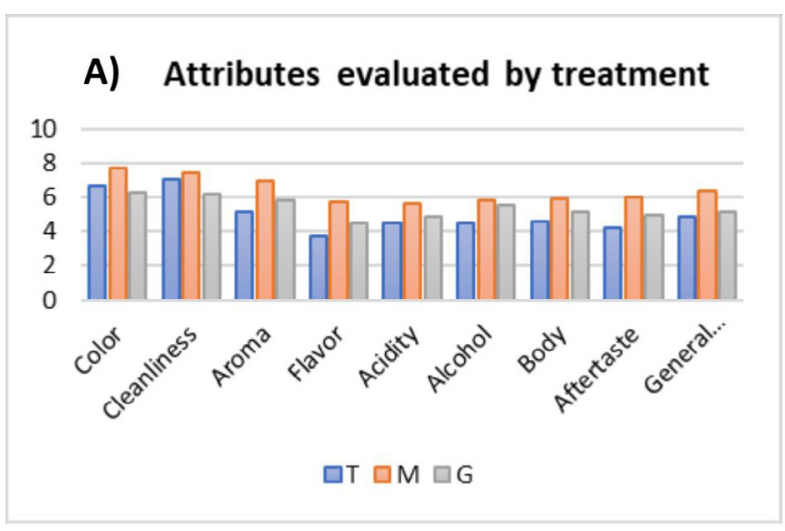

\section{C) Evaluated Attributes for the Coffee Pulp} Infusion

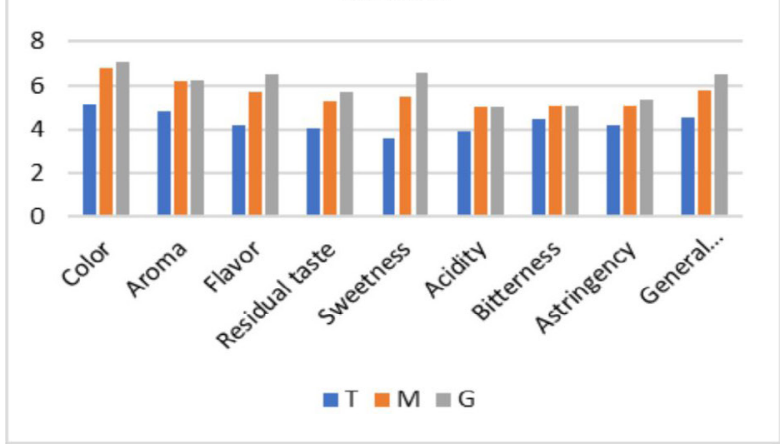

B) Final values of the parameters evaluated by treatment

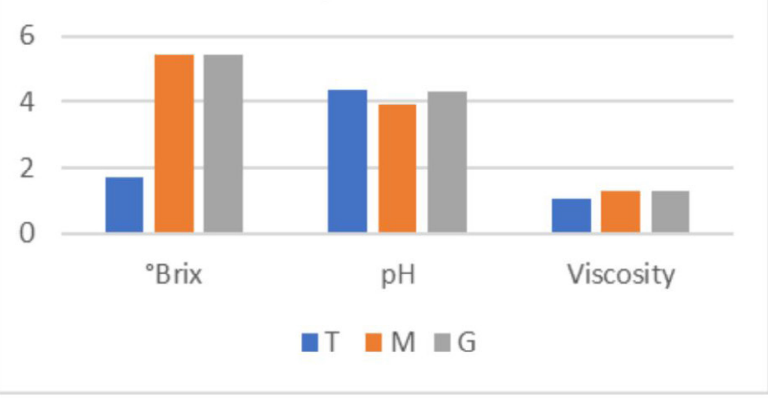

D) Final values of acidity by treatment

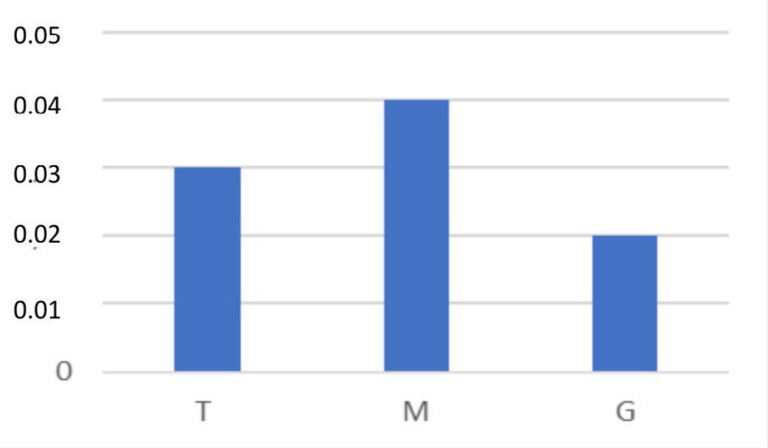

Figure 4: Sensorial Analysis. A: Attributes alcoholic beverage evaluated by treatment. B: The behavior of the final values of the alcoholic beverage parameters. C: Infusion attributes evaluated by treatment. D. Final values of acidity $\left(\mathrm{kg} \cdot \mathrm{L}^{-1}\right)$.

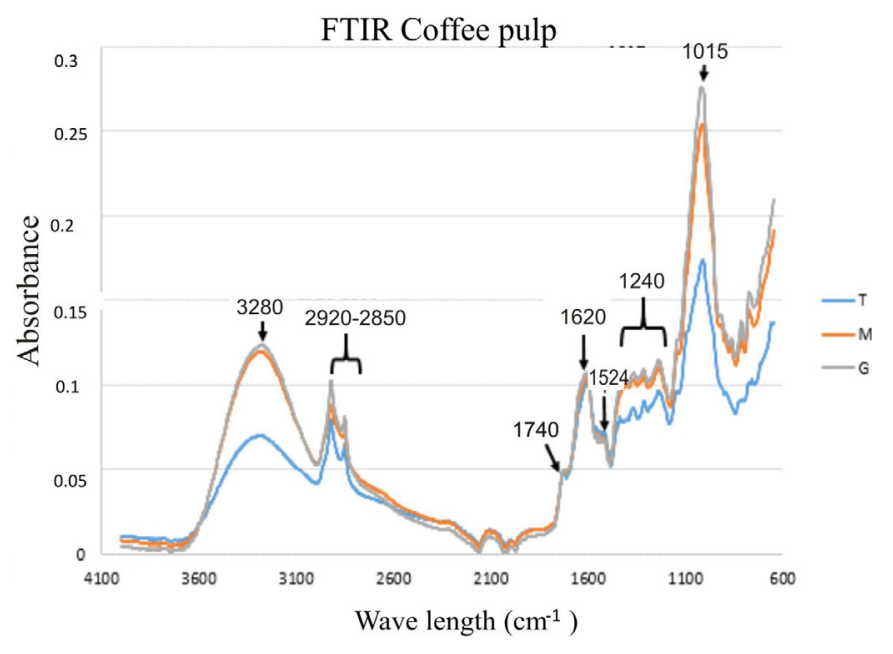

Figure 5: Spectra obtained for coffee pulp by treatment.
For coffee pulp treatments, a peak in the $3280 \mathrm{~cm}^{-1}$ band is evident for $\mathrm{H}_{2} \mathrm{O}$ where $\mathrm{M}$ and $\mathrm{G}$ present higher absorbance compared to $\mathrm{T}$. This wavelength coincides with that mentioned by (Chaplin, 2012) the liquid water stretching band $\left(\mathrm{H}_{2} \mathrm{O}\right)$ is presented in $3490-3280 \mathrm{~cm}^{-1}$

In the range of $3000-2700 \mathrm{~cm}^{-1}$ there are two peaks in a length of $2920 \mathrm{~cm}^{-1}$ and $2850 \mathrm{~cm}^{-1}$ related to caffeine. This wavelength coincides with those mentioned by (Craig; Franca; Oliveira, 2012a). The first study, which associated the bands 2922, 2852 (Craig; Franca; Oliveira, 2011) and $1658 \mathrm{~cm}^{-1}$ with caffeine excitation. It is evidenced that the treatments in these peaks present similarity in the absorbance corresponding to caffeine.

In the wavelength range of $1650-1600 \mathrm{~cm}^{-1}$, there are peaks related to caffeine. The presence of absorption peaks 
in the region of $1450-1000 \mathrm{~cm}^{-1}$ is associated with esters as chlorogenic acids. Also, wavenumbers ranging between 1700 $1600 \mathrm{~cm}^{-1}$ are related to caffeine concentration and chlorogenic acid $\left(1603 \mathrm{~cm}^{-1}\right)$. The range of $1242-1218$ belong to saccharose and 1065-2010 with arabinogalactans (Barrios-Rodríguez, Collazos-Escobar and Gutiérrez-Guzmán (2021).

For Craig Franca and Oliveira (2012b) lipids have absorbance at $1740 \mathrm{~cm}^{-1}$ and for Franca (2018) these can occur in the range of $1743 \mathrm{~cm}^{-1}$. In the spectrum, the peak associated with these lengths was expressed in the $1740 \mathrm{~cm}^{-1}$. There is similarity in the interaction of absorbance between coffee pulp treatments.

There is a peak in the band of $1620 \mathrm{~cm}^{-1}$ related to caffeine which is associated to that mentioned by (Craig, 2018) where caffeine presents vibrations in 1643-1625 cm ${ }^{1}$; the treatments present the same peak and interaction with respect to this compound.

The predominant amino acid Tyrosine (Tyr) is presented in the wavelength of $1524 \mathrm{~cm}^{-1}$. It is within the range mentioned by (Barth; Zscherp, 2014) 1518-1602 $\mathrm{cm}^{-1}$, a similar behavior is evident between treatments.

Chlorogenic acid presents its highest excitation peak at $1240 \mathrm{~cm}^{-1}$ which is within the range mentioned by (Craig; Franca; Oliveira, 2012b) which presents an excitation band in the ranges of $1450 \mathrm{~cm}^{-1}-1050 \mathrm{~cm}^{-1}$. The treatments of coffee pulp $\mathrm{M}$ and $\mathrm{G}$ present similarity in terms of absorbency of this acid, compared to $\mathrm{T}$ which presents lower absorbency.

Carbohydrates are identified at a wavelength of 1015 $\mathrm{cm}^{-1}$ where $\mathrm{M}$ and $\mathrm{G}$ treatments show similar behaviors, with more elevation of absorbance for $G$, with respect to $T$ that presents a peak of lower absorbance. According to (Craig; Franca; Oliveira., 2011), carbohydrates are presented in a range of $1130-950 \mathrm{~cm}^{-1}$, the peak obtained is in the range already mentioned.

\section{DISCUSSION}

During fermentation there are changes in physicochemical properties about the presence of $S$. cerevisiae var Bayanus. The reduction of soluble solids is since the yeasts present in the must consumed the sugars to transform them into alcohol. It can be deduced that $S$. cerevisiae var. Bayanus presented a short latency period and a high speed in the transformation of sugars into alcohol (Oviedo; LozanoVera; Amorocho-Cruz, 2018). This is especially evident in M and $\mathrm{G}$, which initially presented values of $16^{\circ}$ Brix compared to $\mathrm{T}$ treatment that presented a value of 3.70 .

As soon as a high content of initial acidity generates a low speed of fermentation and it is observed that the treatments begin with low acidity and as time passes it increases gradually. According to Marin-Lopéz et al. (2003), when the fermentation process passes, catabolic processes begin due to the degradation of the cell membrane and the presence of chemical compounds and microorganisms that are derived from this process, thus contributing to the increase in acidity.

Viscosity tends to decrease over time, according to Nurgel (2005) the concentrations of ethanol and sugar play a primordial role; viscosity increases in a linear way with the concentration of sugar or ethanol up to a certain threshold from which it decreases.

According to NTC 708 (2008) for fruit wines, the minimum range of alcohol is 6 , without establishing a maximum value. Thus, the products obtained in $M$ and $G$ treatments are within the stipulations of the above-mentioned standard. The alcohol content of the $\mathrm{T}$ one is low in comparison with those obtained in the $\mathrm{M}$ and $\mathrm{G}$ treatments and alcoholic fermentation is not developed in T. It indicates that the presence of sugars in greater quantity favored the metabolic activity of $S$. Cerevisiae var Bayanus specifically for clear wines.

In the case of to alcoholic beverage of coffee pulp, the $\mathrm{pH}$ G showed an increase in $\mathrm{pH}$ from 4.20 to 4.33 ; in the $\mathrm{T}$ and $\mathrm{M}$ treatments took lower values from 4.41 and 4.13 to 4.39 and 3.93. The $\mathrm{M}$ treatment complies with the $\mathrm{pH}$ to be considered as fruit wine according to NTC 708 (2008). Starowicz and Granvogl (2020) presents mead values between 2.74 to 4.90 for a honey of different origin in other latitudes, our treatments have a date in this range.

The acidity of the $\mathrm{T}$ and $\mathrm{M}$ drinks increased during the ripening process, compared to $\mathrm{G}$ which showed a decrease in acidity. Starowicz and Granvogl (2020) mentioned that organic acids are an important group of compounds that influence the organoleptic properties of fermented beverages. In the case of mead content of organics acid change during fermentation.

Physicochemical characterization of coffee pulp infusion, the soluble solids ( ${ }^{\circ}$ Brix) of the coffee pulp infusion of the $M$ and $G$ treatments present statistically significant differences $(p<0.005)$ for $T$. This is due to the adherence of the sweeteners honey and sugar cane juice to the coffee pulp. It is evident that for $\mathrm{pH}$, the infusions of the treatments differ statistically between them and their values tend to be acidic on the $\mathrm{pH}$ scale.

In general, the infusions presented characteristics of sweet notes, pleasant acidity, refreshing, and pleasant colors for the consumer.

The physicochemical and microbiological analyses carried out during the whole fermentation process served as a base to determine some relationships between variables. For example, when the soluble solids are stabilized the fermentation process should be stopped. Acidity and $\mathrm{pH}$ are different from each other, but their behaviors affect each other, viscosity depending on the concentration of soluble solids that food presents. In this project, the drinks produced from the coffee pulp showed a low viscosity liquid, with values similar to water. 
The honey and the juice of sugar cane are products that present high values of sugars in their composition, which allows them to be used in processes of elaboration of alcoholic drinks as natural sweeteners. Furthermore, it has been demonstrated that the union of these products taking place in Colombia, and in particular in the department of the Huila with the pulp of coffee, generated drinks with outstanding organoleptic characteristics such as sweetness, herbal fragrances, pleasant acidity, fancy infusion color, among others and with acceptance of the public.

FTIR applied to the coffee pulp of the treatments indicates the presence of carbohydrates, lipids, chlorogenic acid, caffeine; these compounds are of special interest because caffeine and chlorogenic acid are a benefit to health as an anti-inflammatory, anti-obesity, and other effects to verify in vivo studies (Macheiner et al., 2019). This work showed that is a convenient mix coffee pulp by its compounds with sugar cane juice or honey for giving better sensorial characteristic.

\section{CONCLUSIONS}

In this study, it can be concluded that the agroindustrial residues of coffee processing (coffee pulp) are an important source in obtaining value-added products such as bioethanol, fermented beverages, and infusions which present organoleptic characteristics similar to tea.

\section{REFERENCES}

708, N. T. C. Bebidas alcoholicas, Vino de frutas quinta actualización (Alcoholic beverages, Fruit wine fifth update). 2008. Bogota. Colombia : Colombian Institute of Technical Standards and Certification. ICONTEC. Available in: https://tienda.icontec.org/gp-bebidas-alcoholicas-vinosde-frutas-ntc708-2000.html >. Access in: July, 02, 2021.

BARRIOS-RODRÍGUEZ, Y.; COLLAZOS-ESCOBAR, G. A.; GUTIÉRREZ-GUZMAN, N. ATR-FTIR for characterizing and differentiating dried and ground coffee cherry pulp of different varieties (Coffea Arabica L.). Engenharia Agrícola, 41(1):70-77, 2021.

BONILLA-HERMOSA, V. A.; DUARTE, W. F.; SCHWAN, R. F. Utilization of coffee by products obtained from semiwashed process for production of valueadded compounds. Bioresource Tecnology, 166:142-150, 2014

BRAHAM, J. E. Pulpa de café: Composición, tecnología y utilización. Guatemala: Instituto de Nutrición de Centro América y Panamá, Guatemala. 1978. 152p.

\section{CORRO G.; PANIAGUA L.; PAL U.; BAÑUELOS}

F., ROSAS M. Generation of biogas from coffeepulp and cow-dung co-digestion: Infrared studies of postcombustion emissions. Energy conversión and Management, 74:471-481. 2013.
CRAIG A. P. et al. Mid infrared spectroscopy and chemometrics as tools for the classification of roasted coffees by cup quality. Food Chemistry, 245:1052-1061. 2018.

CRAIG, A. P.; FRANCA, A. S.; OLIVEIRA, L. S. Evaluation of the potential of FTIR and chemometrics for separation between defective and non-defective coffees. Food Chemistry, 132:1368-1374, 2012a

CRAIG, A. P.; FRANCA, A. S.; OLIVEIRA, L. S. Discrimination between defective and non-defective roasted coffees by diffuse reflectance infrared Fourier transform spectroscopy. LWT, 2(47):505-511, 2012 b.

CRAIG, A. P.; FRANCA, A.; OLIVEIRA, S. Discrimination between immature and mature green coffees by attenuated total reflectance and diffuse reflectance Fourier Transform Infrared Spectroscopy. Food Science, 8(76):C1162-C1168, 2011.

CHAPLIN, M. Water Absorption Spectrum. 2012. Inglaterra: Commons Attribution Noncommercial. 8. Available in: <http://www.infotc.co.kr/bin/minihome/ upload/7588/pds/upload/Water\%20absorption\%20 spectrum.pdf $>$ Access in: July, 02, 2021.

\section{CHIRAL BOIX A, M. N. Propiedades fisicas de los} alimentos. 2012. Valencia : Polytechnic University of Valencia . Available in: <https:/www.buscalibre.com.co/ libro-propiedades-fisicas-de-los-alimentos-amparo-chiraltboix/9788483631584/p/4110765>. Access in: July, 02, 2021.

DUARTE, A. et al. Economic, environmental, and social assesment of bioethanol production using multiple coffee crop residues. Energy, 216:119170. 2021.

ESQUIVEL, P.; JIMÉNEZ, V. M. Functional properties of coffee and coffee by-products. Food Research International, 46(2):488-495.

\section{GARCÍA-FREITES, S.; RÖDER, M.; THORNLEY, P.} Environmental trade-offs associated with bioenergy from agri-residues in subtropical regions: A case study of the Colombian coffee sector. Biomass and Bioenergy, 140:105581, 2020.

MACHEINER, L. et al. Green coffee infusion as source of caffeine and clorogenic acid. Journal of Food Composition and Analysis, 84:102307, 2019.

MARIN-LOPÉZ, S. A. P. et al. Cambios físico y quimicos durante la maduración del fruto del café. Cenicafé, 54(3):208-225, 2003.

MARTINEZ-SAEZ, N. et al. A novel antioxidant beverage for body weigh control based on coffee silverskin. Food Chemistry, 150:227-234, 2014. 
NURGEL, C. P. G. Contribution of glycerol, ethanol and sugar to the perception of viscosity and density elicited by model white wines. Journal of of texture study, 36(3):303-323, 2005.

OVIEDO-ARBELÁEZ, M.; LOZANO-VERA, J.; AMOROCHO-CRUZ, C. M. Physicochemical and microbiological characterization of blackberry (Rubus glaucus Benth) wine, El Hobo (Huila). DYNA, 85(207):107-112, 2018.

PANDEY, A. et al. Biotechnological potential of coffee pulp and coffee husk for bioprocesses. Biochemical Engineering Journal, 6(2):153-162, 2000.

PUSHPA, S.; NAIDU, M. M. Sustainable management of coffee industry by-products and value addition - A review. Resources, Conservation and Recycling, 66:45-58, 2012.
RODRÍGUEZ, N., D. ZAMBRANO.; C. RAMÍREZ. Manejo y disposición de los subproductos y de las aguas residuales del beneficio del café. Cenicafé, manual del cafetero colombiano: Investigación y tecnología para la sostenibilidad de la caficultura, 39(8):111-136, 2011.

RODRÍGUEZ, N. Producción de alcohol a partir de la pulpa de café. Cenicafé, 64(2):78-93. 2013

STAROWICZ, M.; GRANVOGL, M. Trends in food science $\&$ technology an overview of mead production and the physicochemical, toxicological, and sensory characteristics of mead with a special emphasis on flavor. Trends in food science \& Technology, 106:402-416, 2020.

ZIELINSKA, D.; SZAWARA-NOWAK, D.; ZIELINSKI, H. Antioxidative and anti-glycation activity of buckwheat hulk tea infusion. Internacional Journal of Food Properties, 16(1):228-239, 2013. 